\title{
Automatic detection of avalanches and debris flows by seismic methods
}

\author{
Bjarni BESSASON, ${ }^{1}$ Gísli EIRÍKSSON, ${ }^{2}$ Óđinn THÓRARINSSON, \\ Andrés THÓRARINSSON, ${ }^{3}$ Sigurður EINARSSON ${ }^{3}$ \\ ${ }^{1}$ University of Iceland, Hjarðarhagi 2-6, IS-107 Reykjavík, Iceland \\ E-mail: bb@hi.is \\ ${ }^{2}$ Icelandic Public Roads Administration, Dagverðardal, IS-400 Ísafjörður, Iceland \\ ${ }^{3}$ Vista Engineering, Höfðabakki 9c, IS-110 Reykjavík, Iceland
}

\begin{abstract}
The road along the Óshlí̉ hillside in the West Fjords region of Iceland is one of the most hazardous roads in Iceland due to avalanches, rockfalls and debris flows. The road has little traffic, but nevertheless traffic accidents caused by the severe conditions at the site are common. A number of avalanche tracks are found on the hillside. In some of these tracks, avalanches occur more frequently than in others. When there is an avalanche threat, avalanches generally flow over many tracks in a short time. Monitoring vibrations in the tracks with the highest avalanche frequency can indicate when avalanches start flowing down the hillside in a snowstorm, and avalanche hazard can then be declared with the specific site indicated. The same methodology can be used for rockfalls and debris flows, which are strongly affected by weather conditions and typically occur in clusters. Based on this knowledge, a research project was initiated in February 1996 with the objective of developing an automatic system based on seismic measurements to detect and analyze avalanches on the Óshlío hillside and to instantly send a warning to a control station.
\end{abstract}

\section{INTRODUCTION}

Iceland is a land of natural hazards. These hazards vary widely and consist of threats from major earthquakes, volcanic eruptions, ash fall, lava flows, catastrophic flooding from glaciers, drift ice from the north polar regions, severe weather conditions and avalanches. Among these, avalanches have caused the most casualities.

Iceland was settled in the 8th century. The first known saga about people killed in an avalanche in Iceland is from the year 1118. Since then there has been a long history of catastrophic avalanches. It has been estimated that since the settlement of Iceland the average number of deaths from avalanches per century has been $\sim 200$. Given the low population of Iceland through the ages, this number of casualties has had a very high impact on the society.

Avalanches are still a threat in Iceland. In January 1995 a major snow avalanche struck the village of Súdavík in the West Fjords (Fig. 1), killing 14 people. In October the same year another avalanche hit the village of Flateyri, also in the West Fjords (Fig. 1), killing 20 people. In addition to the casualties, a number of houses and some infrastructure were damaged. The population of Flateyri was $\sim 400$ and that of Súdavík 200 at the time the avalanches struck. These two catastrophic events have led to new methods of evaluating avalanche hazards in Iceland and new criteria have been established. All means are used to reduce the danger of avalanches, including monitoring of hillsides. A number of new earthworks and avalanche defences have been built where avalanches are a major threat.

Avalanches, as well as rockfalls and debris flows, are strongly correlated with weather conditions. Precipitation, wind direction and wind speed affect accumulation of snow and avalanches, whilst precipitation, along with thawing and ablation in the spring, affects rockfalls as well as debris flows. When there is an avalanche threat in some region or on some hillside, avalanches often flow along many paths in a very short time. Monitoring the paths with the highest avalanche frequency provides information and an alert on when an avalanche has started moving down a hillside in a snowstorm. This allows avalanche hazard warnings to be issued for that hillside and at other sites with similar topography and weather conditions. A similar methodology can be used for rockfalls and debris flows, as they also tend to occur in clusters.

The main aim of this paper is to describe the monitoring, automatic detection and alerting system that has been developed for the Óshlíf road. This road is particularly

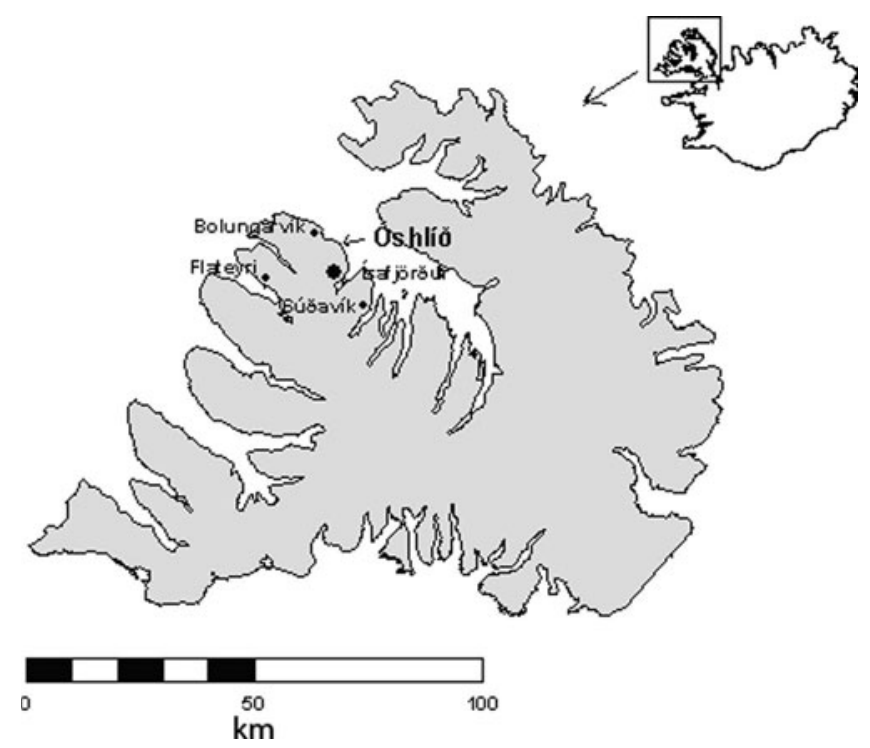

Fig. 1. The West Fjords in northwest Iceland and the location of the Óshlío hillside. 


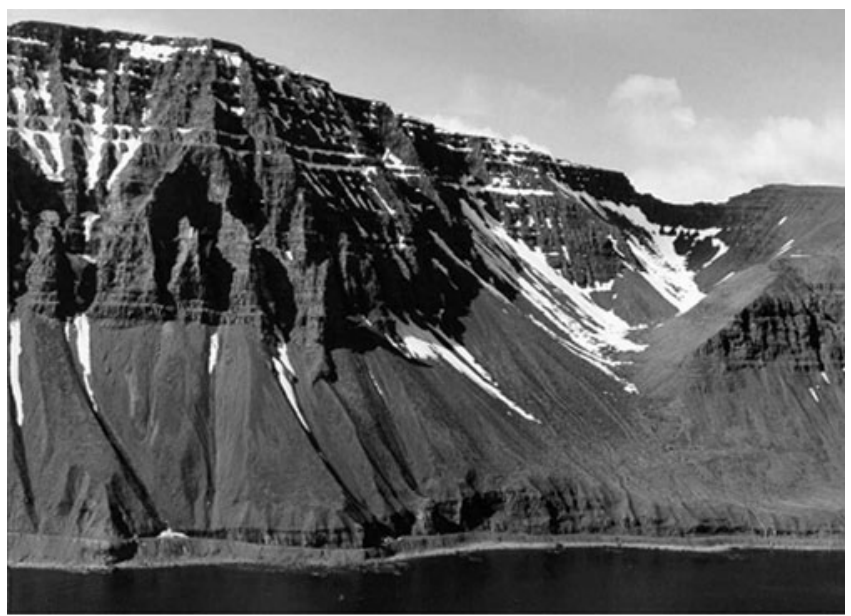

Fig. 2. The Óshlíð hillside and the road close to sea level.

exposed to avalanches, rockfalls and debris flows, and is one of the most hazardous roads in Iceland.

\section{SEISMIC SIGNALS}

Several methods can be used to detect avalanches, rockfalls and debris flows. Methods can be based on acoustic signals, seismic signals, video records, photographic monitoring systems or on combinations of these.

Monitoring systems based on seismic signals are most common and have been used to study and monitor avalanches and debris flows for many years. One of the earliest studies was by Lawrence and Williams (1976).

In Japan, scientists used seismic signals to analyze avalanches in Niigata on 26 January 1986. More work has been carried out in this area in Japan, where the seismic signals caused by avalanches have been compared to seismic signals from earthquakes. The characteristics of seismic signals from avalanches have been studied and analyzed by Kishimura and Izumi (1997).

In France a research team from the Snow Research Centre of the French Metereological Office initiated a project in 1992 for real-time seismic detection of avalanches in the Alps (Leprettre and others, 1996). In a 3 year period, $\sim 300$ events were recorded. About 15\% of these events were caused by avalanches, whilst the rest were triggered by earthquakes, blasts, animals, helicopters, vehicles and thunderstorms. The conclusion was that it was insufficient to record only the seismic signals at the site. Reliable methods had to be found for automatic avalanche signal recognition. Methods based on signal analysis were introduced for this purpose by Leprettre and others (1996).

In Spain the avalanche team of the University of Barcelona have carried out a number of studies of seismic signals from avalanches (e.g. Surinach and others, 2000; Biescas and others, 2003). Surinach and others (2000) used signals recorded at distances of up to $3 \mathrm{~km}$ from the avalanche run-out zone. The studies indicated that each path has its own characteristic seismic signal.

In Norway, geophones have been used in alert systems for roads. The geophones were located in avalanche paths above the road to be protected. When the sensor detected a signal value that exceeded a predefined level, the traffic was alerted by light and sound signals (NPRA, 1994). Although the idea was simple it did not work well in all cases. There were problems in choosing a reasonable threshold level for the geophones, both to avoid false warnings (too low a level) and not to miss real events (too high a level). In addition, there were problems with non-physical spikes or electronic noise that gave false warnings.

Monitoring of debris flows is also well known and has been carried out at many different sites (e.g. Marchi and others, 2002).

In this project we focus on seismic signals as the main indicator for detecting events, i.e. avalanches, rockfalls and debris flows.

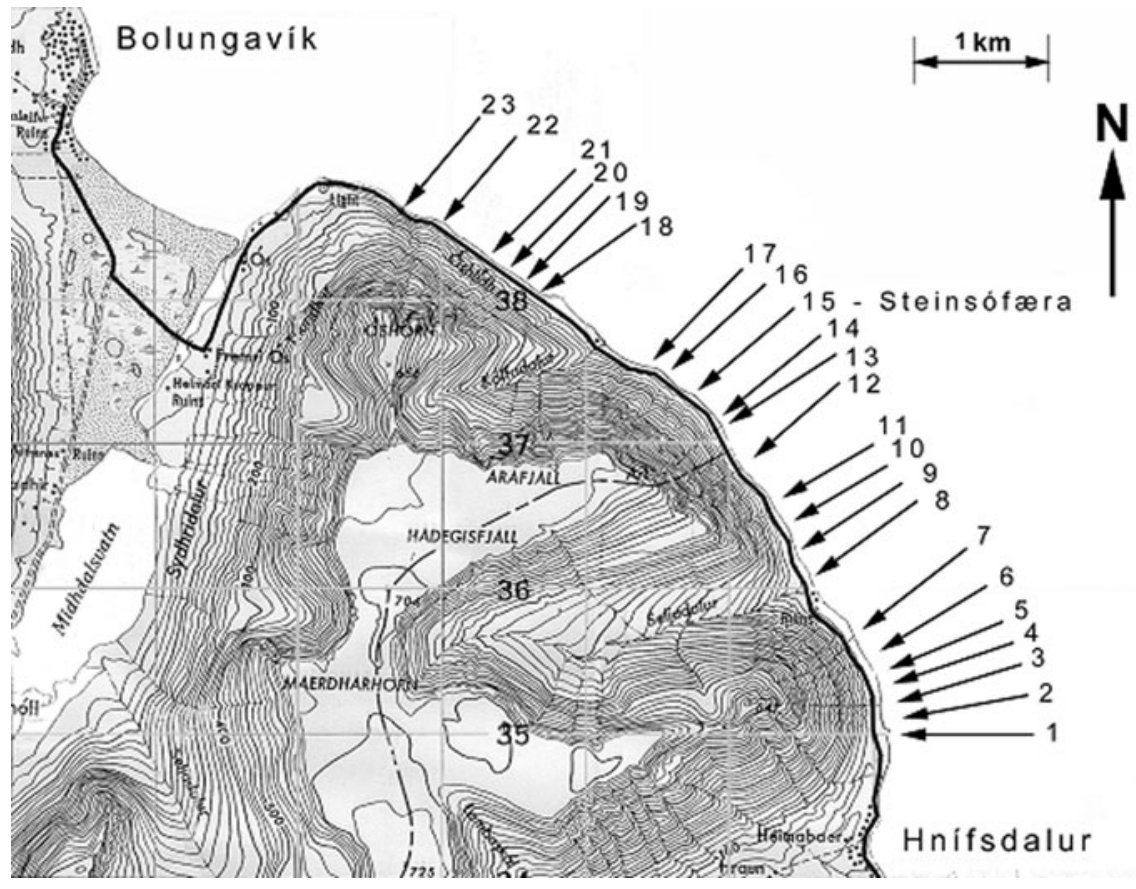

Fig. 3. The road along the Óshlí hillside, showing 23 known avalanche paths. 


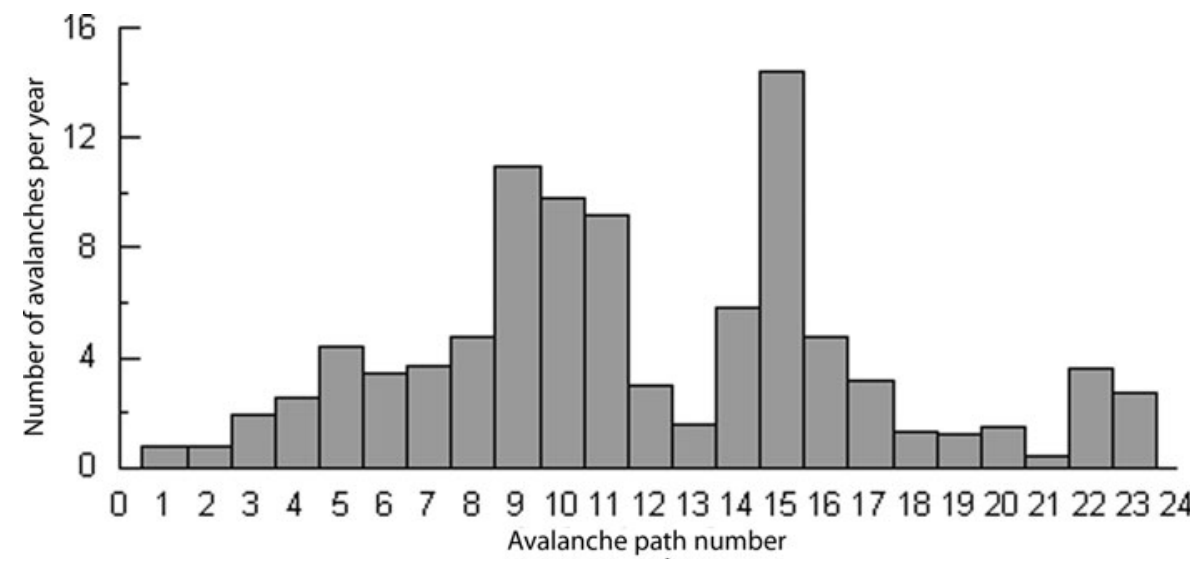

Fig. 4. Number of avalanches per year that caused closure of the Óshlíd road, based on data from 10 years of observations from 1976 to 1985. The avalanches are classified according to avalanche path number on the Óshlío hillside.

\section{MONITORING AND DETECTION SYSTEM ON ÓSHLÍĐ}

\section{Site conditions}

The West Fjords Peninsula (Fig. 1) in northwest Iceland is known as an avalanche-prone area. The landscape consists of mountains and fjords with a limited amount of flat land. The mountains are relatively low, typically $600-800 \mathrm{~m}$ and in all cases $<1000 \mathrm{~m}$ in height. Most of the mountains have a plateau at the top and a large snow accumulation area. Due to the steep fjords, road construction is in general quite difficult in the region and many roads are exposed to avalanches, rockfalls and debris flows.

The $6 \mathrm{~km}$ long road along the Óshlí hillside between Ísafjörour and Bolungarvík (Fig. 1) belongs to this road category and is one of the most hazardous roads in Iceland. At the top of the $\sim 700 \mathrm{~m}$ high hillside there are prominent scars or cliff belts. Below the cliff belts there are steep and unstable slopes of rock, gravel and sand deposits. These slopes extend all the way down to sea level (Fig. 2). The road along the hillside is excavated into the slope at $\sim 20$ $50 \mathrm{~m}$ a.s.l. The road was first opened as a track in 1949, rebuilt in the 1970s and again in the early 1980s. The average annual daily traffic on the road is 550, based on recordings from 1990 to 1999 (Kristjánsson and others, 2002).

Observations carried out by the Icelandic Public Roads Administration (IPRA) have shown that snow avalanches are frequent in 23 paths on the Óshlí hillside (Fig. 3). In the 10 year period 1976-85 a total of 959 snow avalanches that caused the road to be closed were registered in these paths (Fig. 4). In the four paths with the highest avalanche frequencies, concrete avalanche sheds have been constructed to protect the road. The first shed was built in 1986, covering path 15, and later paths 9-11 were also roofed (Fig. 3). Debris flows and rockfalls are also a great threat to car traffic on the road. The rock in this area is basaltic, with a lot of fissures, cracks and holes, and is therefore quite open to weathering and erosion. The frequency of rockfalls is much higher than the frequency of avalanches. Therefore the IPRA has, in addition to the four avalanche concrete sheds, taken several other countermeasures to ensure safety on the road. A trench has been dug along the side of the road to catch most of the rockfalls. Between the trench and the road there is a layer of gabions to stop rolling stones and other debris from reaching the road. Furthermore, in front of the main avalanche paths, catchment dams have been constructed using a stack of gabions (Fig. 5) or steel retaining walls as the dam material. At the most hazardous segments of the road with respect to rockfalls, there are $5 \mathrm{~m}$ high steel nets stretched between steel columns in order to stop rocks from hitting the road. These countermeasures have proved effective and most of the rockfalls and the small avalanches do not reach the road. Finally, the road is patrolled early every morning and cleared if necessary.

\section{Monitoring system}

In February 1996 the first measurement system (system No. 1) was installed in an avalanche concrete shed in path 15 (Bessason and others, 1999, 2000). The system consisted of an SSA-1 data-acquisition unit (DAQ) and a triaxial Kinemetrics Inc. FBA-23 accelerometer. The accelerometer was located at the top of the hillside wall of the shed. The system had a predefined threshold and only recorded events when motion exceeded this threshold. The sampling frequency was $200 \mathrm{~Hz}$ for each channel and the measurement range was adjusted so that it was $0.001-2.5 \mathrm{~m} \mathrm{~s}^{-2}$. Each recorded event had a $10 \mathrm{~s}$ pre-event and a $10 \mathrm{~s}$ post-event. Remote control and transfer of recorded events from the DAQ was through a modem connection between Óshlí and Reykjavík, where observations were made.

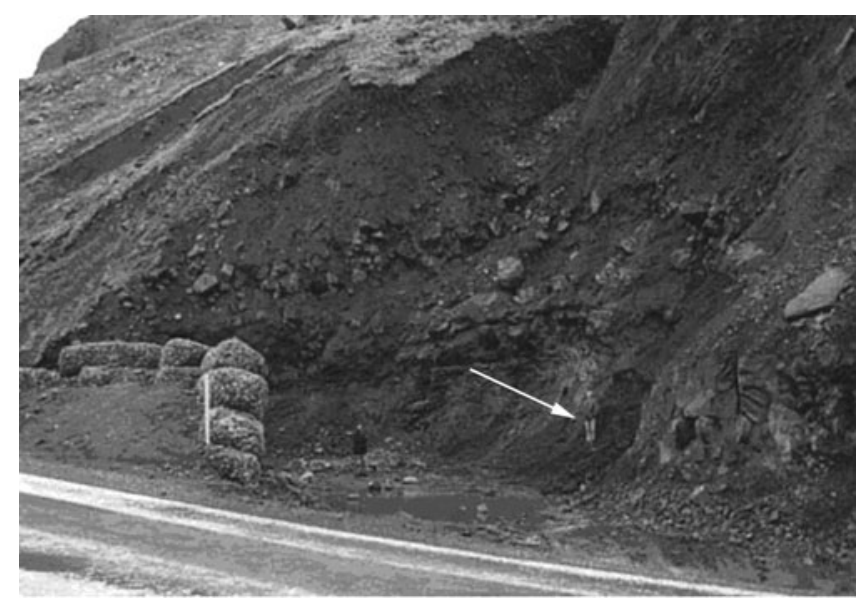

Fig. 5. Catching dam with stack of gabions and location of sensors in path 14. 


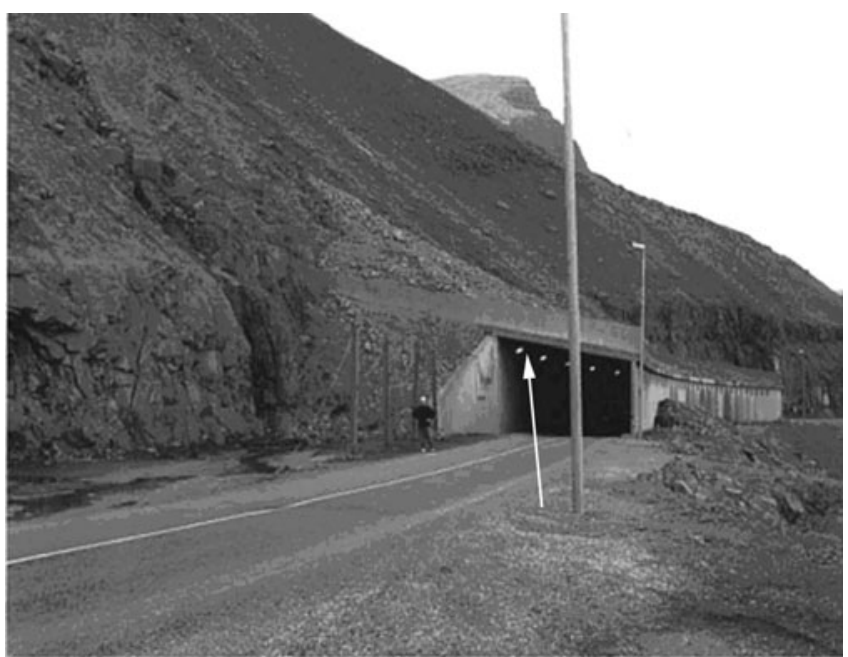

Fig. 6. Concrete shed and location of sensors on the inside hillside wall in path 15 .

In November 1998 the system was upgraded and expanded to cover three paths (system No. 2), i.e. paths 14-16. Figures 5, 6 and 7 show paths 14, 15 and 16, respectively, and the locations of the sensors in each path. The triaxial accelerometer in the concrete shed was replaced with a uniaxial Kinemetrics Inc. FBA-11 accelerometer. The new accelerometer was located at the same place as before in the shed, measuring in a horizontal direction perpendicular to the wall. At the two new avalanche paths, i.e. paths 14 and 16 , the sensors were located on rock outcrop and covered by a steel box bolted to the rock. Path 14 is $120 \mathrm{~m}$ south of the concrete shed in path 15 and the sensor is located about $20 \mathrm{~m}$ from the shoulder of the road. Path 16 is $210 \mathrm{~m}$ north of path 15 and the sensor is located about $30 \mathrm{~m}$ from the shoulder of the road. In addition to the accelerometer in path 16, a Sensor Netherlands SM-6 geophone with natural frequency $4.5 \mathrm{~Hz}$ was installed parallel to the accelerometer in order to obtain experience with this type of sensor. The geophone cost is one-tenth that of an accelerometer. Furthermore, the SSA-1 DAQ was replaced with a Kinemetrics Inc. K2 DAQ. The new system is capable of automatically alerting the control station in Reykjavík, which then collects the measurements and sends out information about any new event that has been recorded. The resolution of the new DAQ is 24 bits (cf. 12 bits for the original DAQ) and the measurement range is $0.01 \mathrm{~mm} \mathrm{~s}^{-2}$ to $9.8 \mathrm{~m} \mathrm{~s}^{-2}$ for the accelerometers and $0.10 \mu \mathrm{m} \mathrm{s}^{-1}$ to $86.6 \mathrm{~mm} \mathrm{~s}^{-1}$ for the geophones.

In August 1999 two geophones were added to the system, one beside the accelerometer in path 14 and one beside the accelerometer in path 15 (system No. 3). Finally, in December 2000 the geophone in the concrete shed was moved to a $2 \mathrm{~m}$ high steel column on the roof of the concrete shed (system No. 4). The steel column is located in the middle of the avalanche path, and during an avalanche it will be hit by the flow and will therefore vibrate violently. This is the present state of the system. Figure 8 shows a schematic diagram of the system, in which three paths (numbers 14-16) of the 23 on the Óshlío hillside are monitored.

\section{Database}

The monitoring system has been running since February 1996. More than 6000 events have been recorded so far,

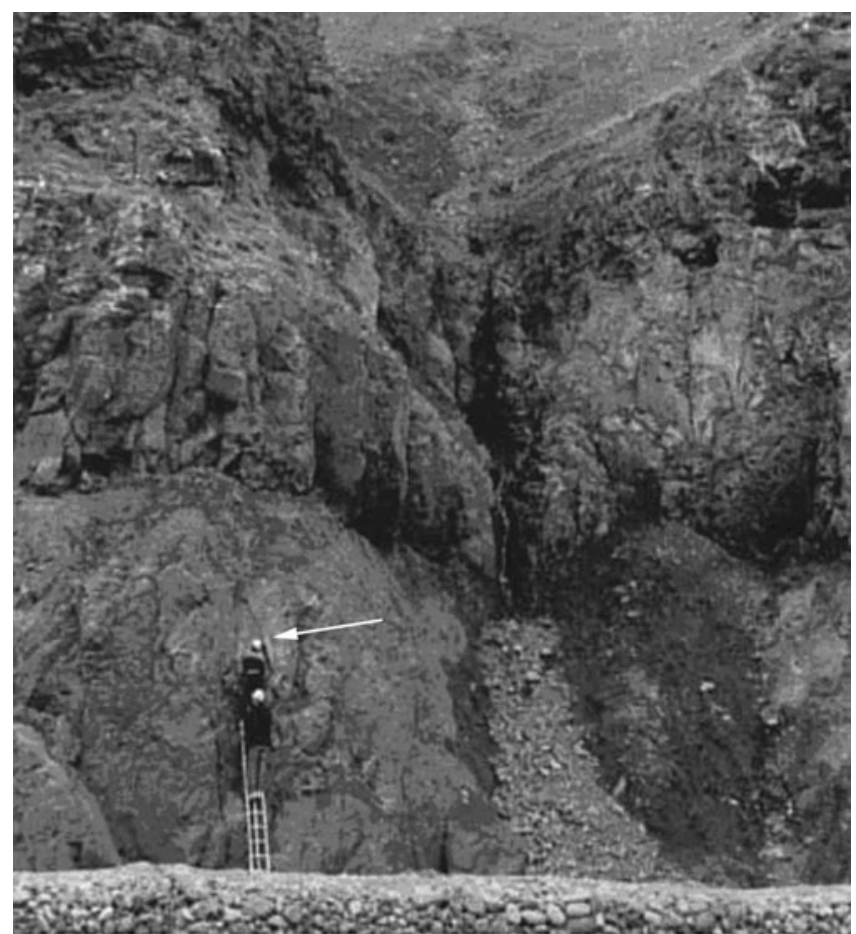

Fig. 7. Location of sensors in path 16.

from road traffic, rockfalls, debris flows, avalanches, earthquakes and maintenance and cleaning work on the road. Every recorded event from the monitoring system is transferred as a file via a telephone link to the control station in Reykjavík (300 km away) where identification is carried out (Fig. 8). In 2004 it was decided to organize the data into a database where they can be viewed, re-analyzed, sorted, etc. It is now possible to view activity in each path over requested time intervals (a week, a month or longer) at any time since the monitoring started.

Most of the recorded events in the database have unknown identity. However, some of them have been identified by field inspection and some by visual inspection of the recorded time histories. Controlled measurements of traffic-induced events also exist. Finally, there are a few events that have been identified as earthquakes because the times and dates can be correlated to known earthquakes in the Icelandic earthquake catalogue. All identified events are marked in the database as 'known events' listed as one of five types:

avalanches

rockfalls and debris flows

earthquakes

traffic

work, i.e. events caused by excavators or other machines doing clean-up work and maintenance.

Rockfalls and debris flows are classified in one group. In many cases the masses coming down the hillside are a mixture of both types and, consequently, are difficult to classify. However, in some cases there are pure rockfall events and these could, and maybe should, be classified as a single group in the future. Traffic events are of no interest except to be able to identify and then ignore them. It should be underlined that the 'known events' are path-dependent and cannot be compared across different paths. This is 


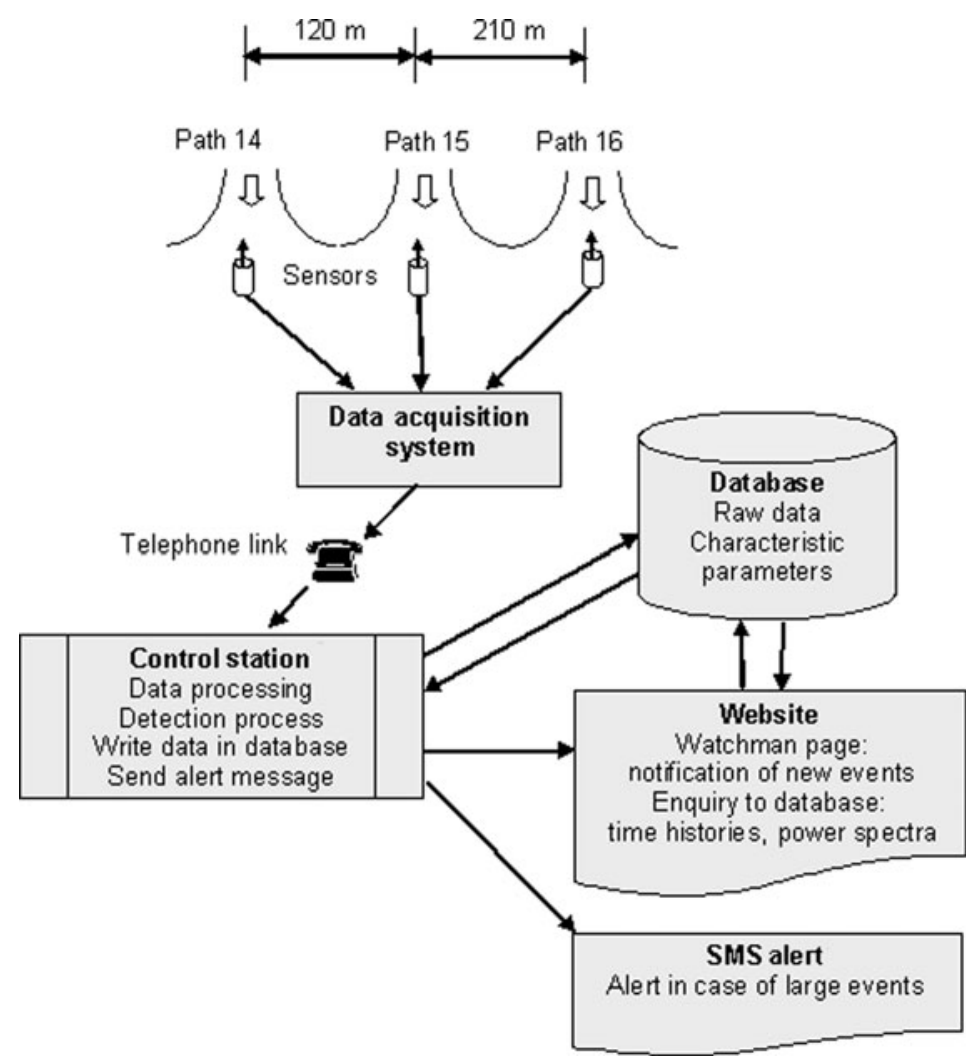

Fig. 8. The basic elements of the detection and alert system in Óshlíd.

understandable as the locations of the sensors are quite different, as shown in Figures $5-7$. The sensors are on rock outcrops in paths 14 and 16, but on the shed wall or on a pole in path 15, which measures structural response rather than ground motion. This path dependency is in agreement with other studies (e.g. Surinach and others, 2000).

\section{Characteristic parameters}

The basis of the detection process is to use known events to identify new events by comparison. A new event for a path is compared to all the known events in the database for the same path and then classified as belonging to the same group as the event in the database that it is most like, i.e. the socalled 'nearest-neighbour method'. There are many approaches we could take to carrying out this comparison. Here, we base the comparison on ten characteristic parameters that are determined from the time series and the power spectrum for a given event. In the present system time series, $x(t)$, from just one sensor, either the accelerometer or the geophone, are used to represent each path. The ten characteristic parameters used in the comparison are as follows.

\section{Peak value, $\alpha_{1}$}

Peak value is the absolute peak value of the recorded $x(t)$ over the total record period:

$$
\alpha_{1}=\operatorname{Max}(|x(t)|) .
$$

Power, $\alpha_{2}$

The power of the signal is found by integrating the square of the signal over the total record duration, $T_{\mathrm{d}}$ :

$$
\alpha_{2}=\int_{0}^{T_{\mathrm{d}}} x^{2}(t) \mathrm{d} t
$$

Total duration, $\alpha_{3}$

Duration of an event can be defined in many ways (e.g. Vanmarcke and Shih-Sheng, 1980). We define it as the duration for which $x(t)$ is greater than twice the standard deviation of the background vibration noise at the given site. The standard deviation of the background noise is found from the first $4 \mathrm{~s}$ in the recorded event, i.e. from the preevent part of the signal. As the event may consist of a combination of pulses and quiet intervals, the above definition of the duration may exclude some of the quiet intervals, e.g. if their intensity is lower than twice the standard deviation of the background noise.

\section{Power duration, $\alpha_{4}$}

Typically a rockfall has one or more intense pulses while the rest of the signal is quiet. This will lead to short power duration as all the power is included in the pulses. The duration of power output of snow avalanches is more spread out, giving a longer power duration than for rockfalls. The power duration is defined as the total time that includes $90 \%$ of the power output. This is calculated by rearranging the time series by sorting the recorded and squared amplitudes with respect to their magnitudes, then selecting the length of signal that includes $90 \%$ of the power.

\section{Impact factor, $\alpha_{5}$}

The impact factor is defined as the ratio of the peak value to the root-mean-square $(\mathrm{rms})$ value of the signal in a $5 \mathrm{~s}$ window around the peak, i.e. the peak is in the middle of the window,

$$
\alpha_{5}=\frac{\alpha_{1}}{\alpha_{\mathrm{rms}}} .
$$

A high impact factor indicates a signal consisting of pulses, for instance caused by a rockfall, while a lower value 


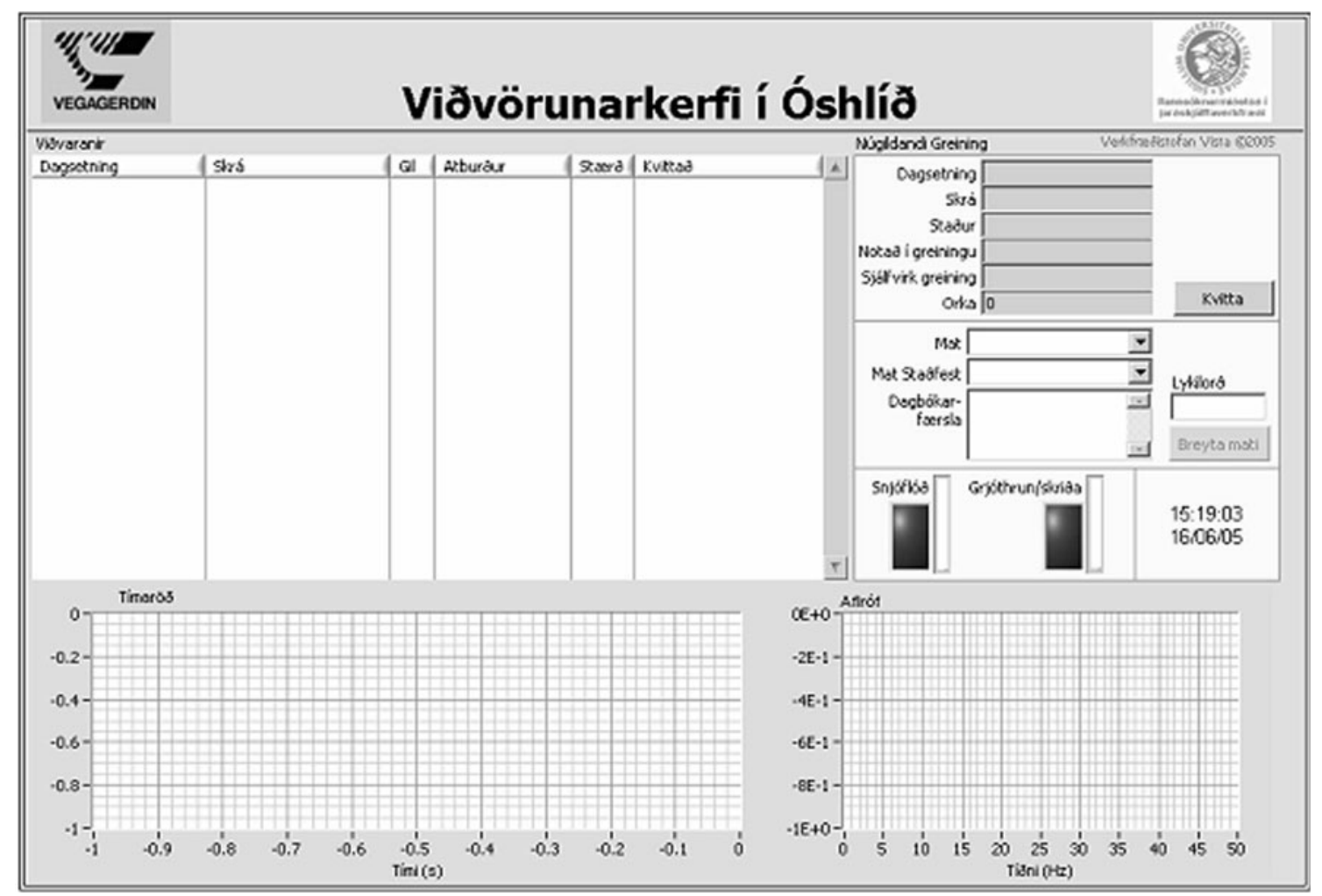

Fig. 9. Screen dump of the watchman page. The watchman page shows all events that have occurred within the preceding 24 hours, giving the type and size (small, medium, large). The time history and the power spectrum of the most recent event are shown at the bottom. (All text is in Icelandic.)

indicates more continuous flow. Using this definition a harmonic sine signal has an impact factor of 1.41 .

\section{Characteristic frequency, $\alpha_{6}$}

The characteristic frequency is determined from the power spectral density, $S_{x}(f)$, of the time series as:

$$
\alpha_{6}=\sqrt{\frac{\int_{0}^{\infty} f^{2} S_{x}(f) d f}{\int_{0}^{\infty} S_{x}(f) d f}} .
$$

The characteristic frequency is an indicator of the dominating frequency in the series.

\section{Half-power bandwidth, $\alpha_{7}$}

The half-power bandwidth of the power spectrum is defined as the width of the frequency band which contains half the power in the spectrum. It is based on the following equations:

$$
\begin{array}{r}
I=\int_{0}^{\infty} S_{x}(f) \mathrm{d} f, \\
\int_{0}^{f_{1}} S_{X}(f) \mathrm{d} f=0.25 I, \\
\int_{0}^{f_{2}} S_{X}(f) \mathrm{d} f=0.75 I, \\
\alpha_{7}=f_{2}-f_{1} .
\end{array}
$$

In Equations (6) and (7) the frequencies $f_{1}$ and $f_{2}$ are the only unknown parameters; they can be found when $I$ is known from Equation (5).
Lower spectral limit, $\alpha_{8}$

The lower spectral limit is found by an equation similar to Equation (6), i.e.

$$
\int_{0}^{\alpha_{8}} S_{x}(f) \mathrm{d} f=0.10 I
$$

This parameter is used to identify some of the traffic-induced events which are characterized by a low-frequency disturbance in the signal which is non-natural. These events can then easily be removed from consideration.

Ratio of maximum to minimum amplitude, $\alpha_{9}$

Some of the recorded events caused by traffic have large non-natural amplitude that is one-sided, i.e. either below or above the zero axis. It seems that there is some strong electronic field connected to the passing vehicle that affects the monitoring system and deforms the recorded seismic signal. For such records the ratio of this non-natural amplitude to the natural maximum of the time series will be considerably above one. This ratio can be determined by:

$$
\alpha_{9}=\frac{\operatorname{Max}\{\operatorname{Max}[a(t)],|\operatorname{Min}[a(t)]|\}}{\operatorname{Min}\{\operatorname{Max}[a(t)],|\operatorname{Min}[a(t)]|\}} .
$$

For most undisturbed or natural events this parameter is close to 1 . This parameter, as well as parameter $\alpha_{8}$, helps to distinguish these signals.

\section{Frequency of maximum value, $\alpha_{10}$}

This parameter is defined as the frequency of the maximum value in the power spectral density, $S_{x}(f)$. For time series recorded in the concrete shed this frequency is in most cases much lower for avalanches than for debris flows and rockfalls. 


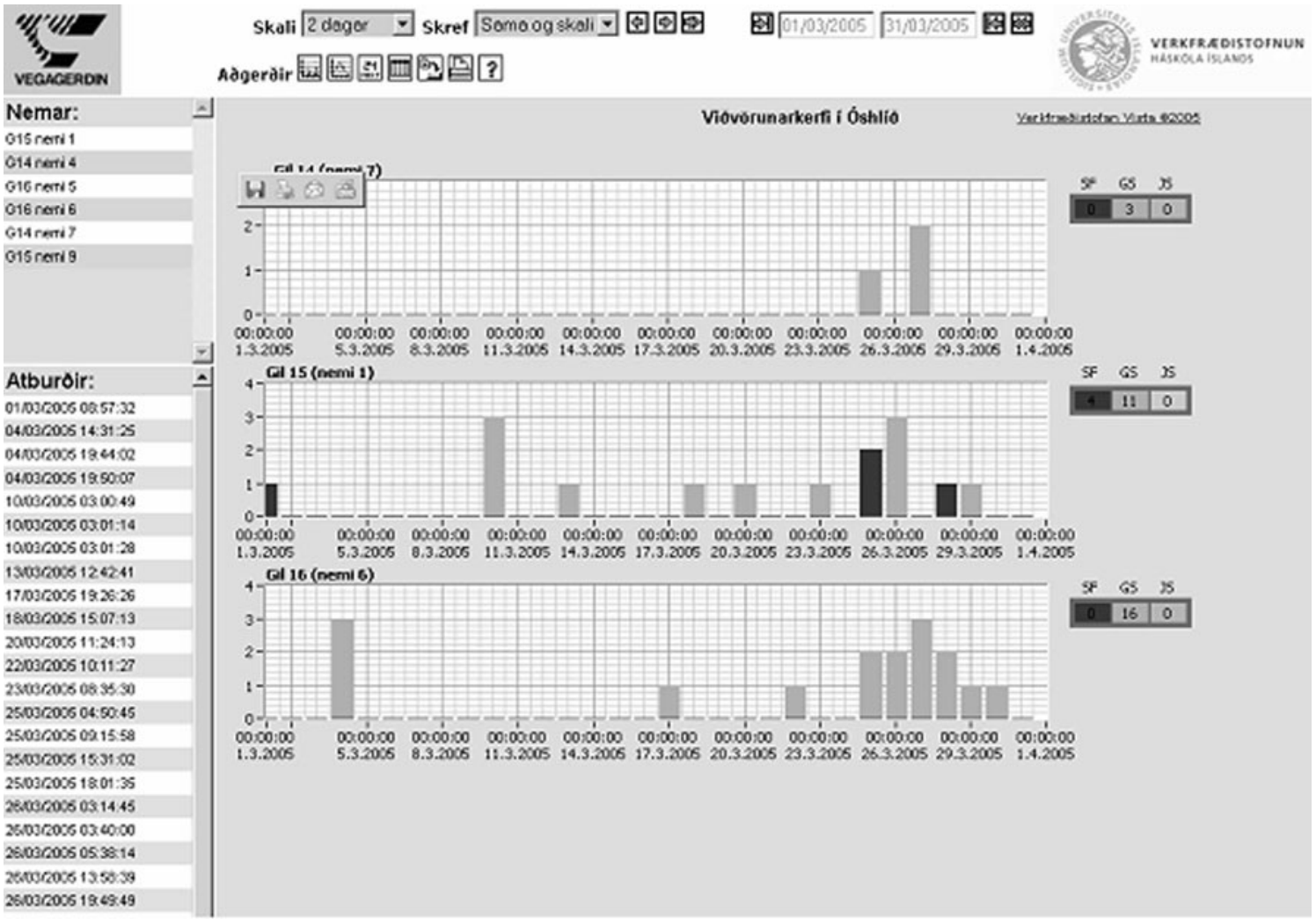

Fig. 10. Screen dump of overview page for all three paths $(14,15$ and 16) with user-defined time period to view. This page shows all detected events in March 2005. (All text is in Icelandic.) SF - avalanches, GS - rockfalls/debris flows, JS - earthquakes.

\section{Detection of an event}

The above ten parameters, which are not unique, are computed for all the 'known events' in the database. Thus, for each path, $k$, there are $N_{k}$ 'known events' in the database and consequently $N_{k}$ sets of the characteristic parameters for that path, i.e.

$$
\bar{\alpha}_{1 j k}, \bar{\alpha}_{2 j k}, \ldots, \bar{\alpha}_{10 j k} \quad j=1,2, \ldots, N_{k} \quad k \in\{14,15,16\} .
$$

When a new event is recorded in path $k$, corresponding

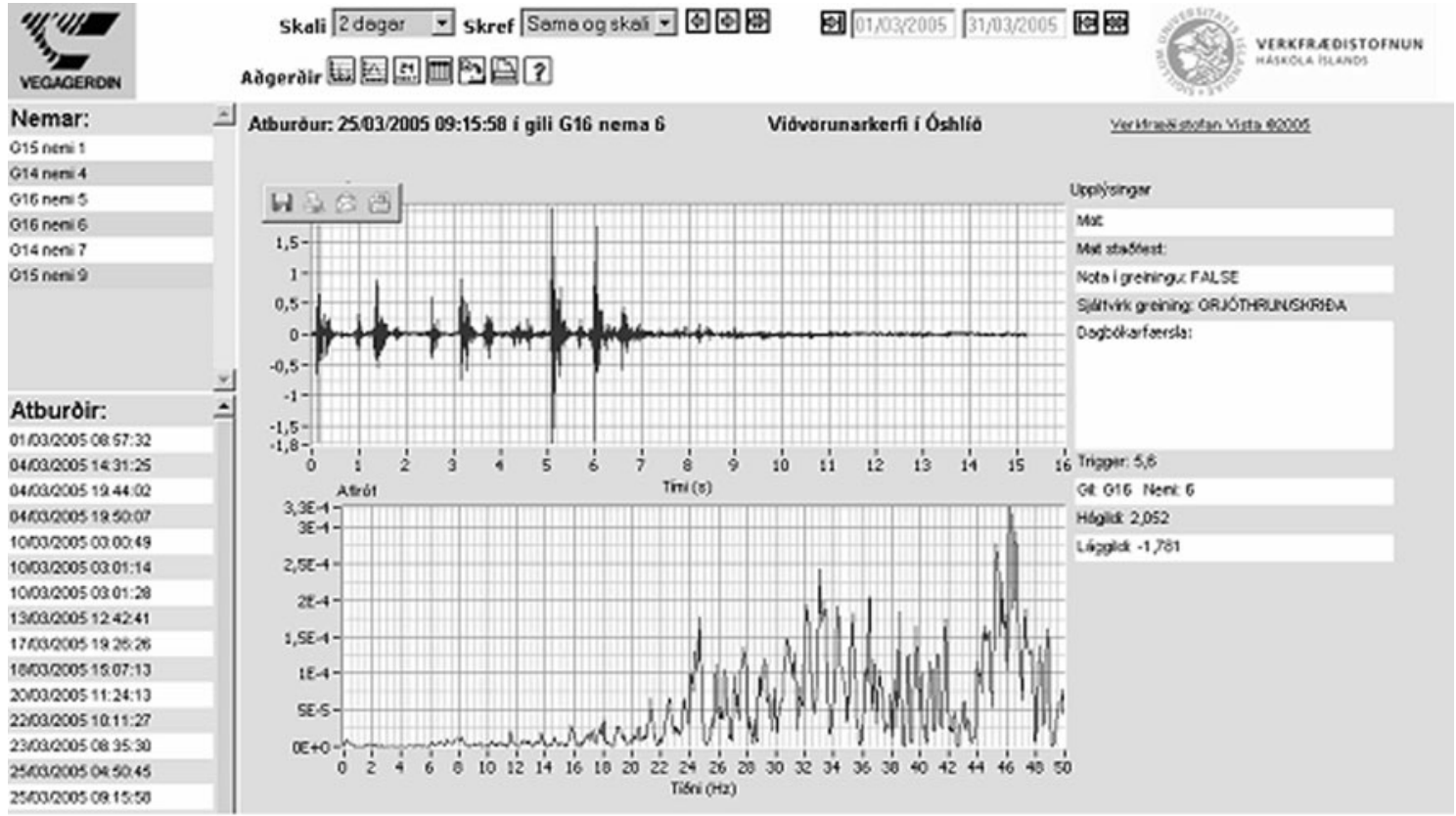

Fig. 11. Screen dump of a page for a single user-defined event. The upper curve shows the time history and the lower curve the corresponding power spectrum. (All text is in Icelandic.) 

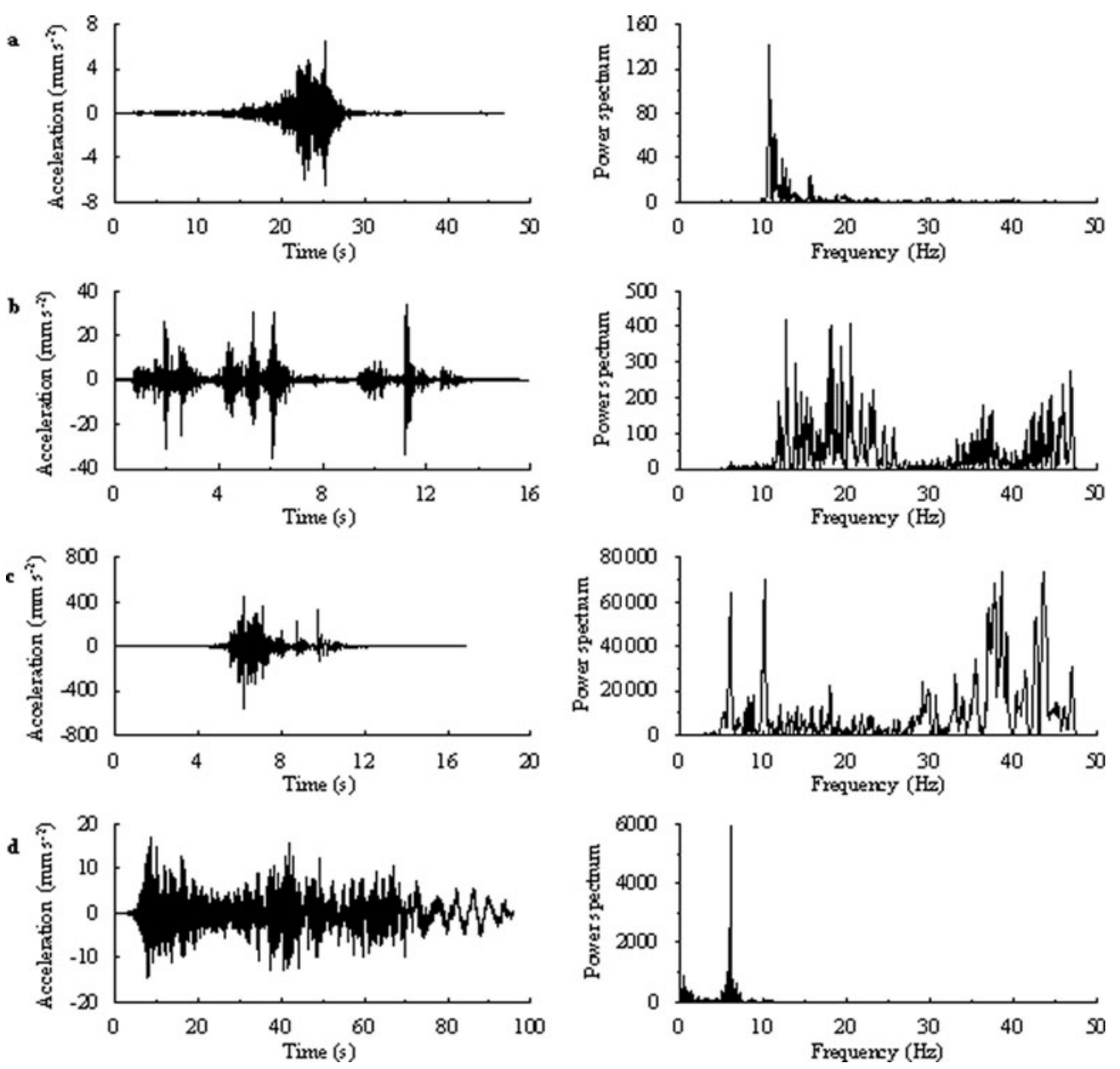

Fig. 12. Recorded events in path 15 (in the concrete shed). The time series are shown on the left with the corresponding power spectra on the right. (a) Truck, (b) rockfall, (c) avalanche and (d) earthquake.

characteristic parameters are computed for the event, i.e.

$$
\alpha_{1 k}, \alpha_{2 k}, \ldots, \alpha_{10 k} \text {. }
$$

The new event is then compared to all known events in avalanche path $k$ in the database by computing the proportional error:

$$
\begin{aligned}
E_{j k}=\sum_{i=1}^{10}\left(W_{i k}\left|\frac{\alpha_{i k}-\bar{\alpha}_{i j k}}{\bar{\alpha}_{i j k}}\right|^{e}\right) \\
j=1,2, \ldots, N_{k} \quad k \in\{14,15,16\},
\end{aligned}
$$

where $W_{i k}$ is a weighting factor which allows some parameters to be assigned more weight than others in the error sum and $e$ is the potential of the proportional error. In this project, $W_{i k}$ is kept equal to 1 for all the parameters and $e=2$. The new event is then group classified as the one in the database which gives the lowest proportional error, $E_{j k}$.

Instead of using only one most-alike event to identify a new event, it is also possible to use three or even more mostalike events in the identification process by using a voting procedure. For instance, let us assume that the system is based on using three most-alike events. If the most-alike event is traffic and the second and third most-alike events are avalanches, the voting procedure would give one vote to traffic and two votes to avalanche. The outcome would be to identify the new event as an avalanche. The implication of such a voting procedure is to improve the quality of the event detection and therefore it is necessary to have some procedure to measure the quality of different detection methods (see next subsection).

Finally, it is possible to define the nature of an event as 'unknown' if the proportional error as defined by Equation (13) exceeds some predefined value. The predefined value can be set by analyzing the quality and reliability of the detection process as described below.

\section{Measure of the quality of the detection process}

A simple and effective way to measure the quality and reliability of the detection process is to use the sample of all the known events to identify the known events one by one. This procedure can be described as follows.

From a sample $\Omega_{k}$ with $N_{k}$ known events from path $k$, i.e. $\Omega_{k}=\left\{x_{1}, x_{2}, x_{3}, \ldots, x_{N k}\right\}$, event $x_{1}$ is picked out and the rest of the sample is then used to identify this event using the characteristic parameters and Equation (13). If the identification is successful the score is 1 , otherwise it is 0 .

This process is repeated for all events, i.e. event $x_{2}$ is next selected from the sample and the rest of the sample used to identify it. Again the score is either 1 or 0.

Having carried out this process for all events, the scores are summed, giving the result, $n_{k}$.

The ratio $n_{k} / N_{k}$ is then found and if this ratio is close to 1.0 it means the detection is close to being $100 \%$ reliable and vice versa. 

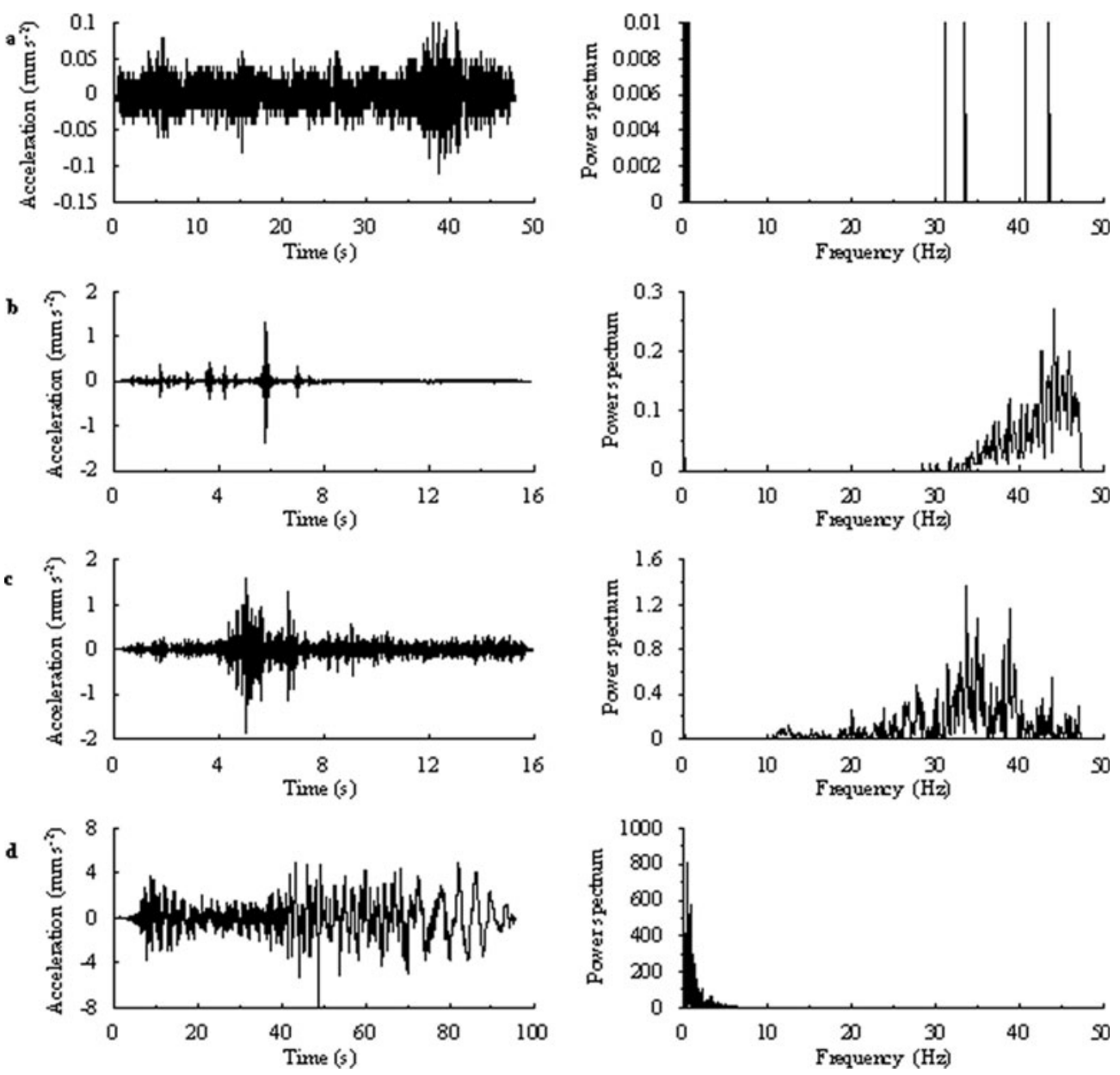

Fig. 13. Recorded events in path 16 (on rock outcrop). The time series are shown on the left with the corresponding power spectra on the right. (a) Truck, (b) rockfall, (c) avalanche and (d) earthquake.

In this way it is possible to evaluate the detection process or variants of it, i.e. using more or fewer parameters, utilizing different weight factors, using a voting procedure or using some other method to detect events.

\section{Size classification}

After detecting and group classifying a new event, the final step is to determine the size as either a 'small', 'medium' or 'large' event, with respect to the path and the group it belongs to. The size sorting is only carried out for events that are group classified as 'avalanches' or 'rockfalls/debris flows'. Traffic-induced events and earthquakes, which are rare, are of less concern. The power parameter, $\alpha_{2}$, is used as an indicator of the size. This parameter indicates a considerable difference between small and large events. It was therefore more convenient to use $\log _{10}\left(\alpha_{2}\right)$ as a measure of the size. Cumulative probability distributions were computed for the size of avalanches and rockfall/debris flow events in each path, separately for all the known events (a total of six distributions). Events that register a power proportion between 0 and $50 \%$ are classified as small, between $50 \%$ and $95 \%$ as medium and above $95 \%$ as large.

\section{Presentation of the results}

The results of the detection process are published on a website, and an alert message is sent via short message service (SMS) to key personnel if the size of a recorded event exceeds some predefined criteria. There are three pages on the website. The main page is the 'watchman page' (Fig. 9), which is designed to be continually open at the watchman's desk. It is automatically updated whenever an event is recorded on the Óshlío hillside, except when the detection process identifies a traffic-induced event. The page shows the date and time of the event, path number, type of event and its size. It shows all events that have occurred within the preceding 24 hours. The watchman has the option to decide that a new recorded event was really an avalanche, a rockfall/ debris flow or an earthquake, and this event is then stored in the database as a 'known event' (a 'true' flag is assigned for the event). In the future this new event, along with the other known events in the database, is used for identifying further events. If the watchman is uncertain about the origin of the event, the event will be stored in the database without the 'true' flag and it will not be used for identifying new events. With this procedure the identification process should become more and more reliable as the number of known events increases with time; in other words, the system is 'learning'.

On a second page, the overview page, one can view the number of recorded events within the preceding 2 days, week, month or within any user-defined time interval for all three paths, i.e. paths 14-16 (Fig. 10). The page also gives the number of events in each category.

Finally, a third page gives the time history and the corresponding power spectrum for an event stored in the database (Fig. 11), selected from the lefthand panel on the overview page. A trained eye can read a great deal from these graphs. 
Table 1. Overview of systems and number of recorded events

\begin{tabular}{|c|c|c|c|c|c|c|c|}
\hline \multirow[t]{2}{*}{ System No. } & \multirow[t]{2}{*}{ Period } & \multirow{2}{*}{$\begin{array}{c}\text { Number of } \\
\text { months }\end{array}$} & \multicolumn{3}{|c|}{ Number of events } & \multirow{2}{*}{$\begin{array}{c}\text { Total number } \\
\text { of events }\end{array}$} & \multirow{2}{*}{$\begin{array}{c}\text { Number of events } \\
\text { per month }\end{array}$} \\
\hline & & & Path 14 & Path 15 & Path 16 & & \\
\hline $1^{*}$ & 19 Feb 1996-19 Oct 1998 & 32.5 & 0 & 303 & 0 & 303 & 9 \\
\hline $2^{\dagger}$ & 20 Oct 1998-17 Aug 1999 & 8.8 & 0 & 169 & 584 & 753 & 86 \\
\hline 3 & 18 Aug 1999-10 Dec 2000 & 15.5 & 590 & 535 & 574 & 1699 & 110 \\
\hline Total & & 120.4 & 1757 & 1823 & 2452 & 6032 & \\
\hline
\end{tabular}

${ }^{*}$ In system No. 1, only avalanche path 15 was instrumented.

†'In system No. 2, only avalanche paths 15 and 16 were instrumented.

\section{OBSERVATIONS}

\section{Overview}

The measurements have been going on for more than a decade; in this paper we consider the results of the first 10 years, from February 1996 to April 2006. Table 1 provides an overview of the number of recorded events. It only shows events recorded on the geophone in path 14 , the accelerometer perpendicular to the wall in path 15 and the geophone in path 16, since these are the sensors that are used to identify new events. Therefore, system No. 1 only contains events from path 15, system No. 2 only events from paths 15 and 16, while the other two systems contain measurements from all three paths. Furthermore, the number of events strongly depends on the trigger value used to initiate an event registration. The sensors in path 15 are located on the avalanche concrete shed and measure structural response, while the sensors in paths 14 and 16 are located on rock outcrops and measure ground motion. The vibration level in paths 14 and 16 is about one-tenth of the vibration level in path 15. The trigger values were changed up and down in the initial phase, to acquire experience and test the results. Since the activation of system No. 3, in August 1999, the trigger values have been kept constant in the sensors, at $1.0 \mathrm{~mm} \mathrm{~s}^{-2}$ in paths 14 and 16 and at $10 \mathrm{~mm} \mathrm{~s}^{-2}$ in path 15 .

As seen from Table 1, the existing system recorded, on average, 52 events per month in these three paths, equivalent to almost two events per day. But, as mentioned earlier, the events come in clusters and many days are quiet and event-free.

\section{Examples}

The basic idea in the classification process is to use known events to identify new ones. Many events have strong

Table 2. Overview of confirmed and classified events in paths 14, 15 and 16

Avalanches Rockfalls/ Earthquakes Traffic Work $^{*}$ debris flows

\begin{tabular}{rrrrrr}
\hline Path 14 & 5 & 76 & 7 & 0 & 0 \\
Path 15 & 93 & 51 & 7 & 123 & 6 \\
Path 16 & 21 & 58 & 0 & 1 & 21
\end{tabular}

*Events caused by excavators and other machines doing clean-up work and maintenance. characteristics that simplify the identification, while other events are more complex. For instance a wet avalanche can contain snow blocks, stones and soil, and therefore its recorded vibrations will have the character of a rockfall or debris flow, etc., and the identification process can be very difficult. In Figure 12, examples of recorded events in path 15 (at the avalanche concrete shed) caused by traffic, rockfalls, avalanches and earthquakes are shown. These examples have characteristics that are strongly correlated with their source and are therefore easy to recognize. Farfield earthquakes can also be recognized due to their low frequency. In Figure 13, similar results are shown for path 16. As can be seen from Figure 13a, the traffic-induced vibrations are well below the trigger value for this path $\left(1.0 \mathrm{~mm} \mathrm{~s}^{-2}\right)$ and the resolution bits in the signal can also be seen. In general, traffic will not trigger the sensors in paths 14 and 16 .

\section{Quality of classification}

Table 2 presents an overview of the identified recorded events on the three avalanche paths. The origin or source of the events has been verified by field investigations or by visual inspection of the time series, along with information about weather conditions. For instance, during summer when there is no snow on the hillside there can obviously be no avalanches. These events are used to identify new events. It must be mentioned that some of these events are from the same cluster, i.e. in a snowstorm there may be many small avalanches flowing along the same path.

In Table 3 the results of the identification process are shown for paths 14, 15 and 16 .

It should be noted that in path 14 there have been only five avalanches and they were not identified as such. The identification process is evidently not sufficiently reliable for detecting avalanches in this path and it must be concluded that the database is too small for this path. The identification process for this path should therefore wait until more confirmed events have been recorded.

The identification process for path 15 shows that the system achieves a good score for detecting events caused by traffic $(93 \%)$. The reliability of detection of avalanches and rockfalls/debris flows is only around $75 \%$, which is at the limit of being acceptable.

The identification process for path 16 shows that the system detects only $43 \%$ of the avalanches correctly, while $71 \%$ of the rockfalls/debris flows are correctly detected. Traffic-induced events do not occur in this path. 
Table 3. Quality of the identification process for paths 14,15 and 16

\begin{tabular}{|c|c|c|c|c|c|c|}
\hline Path & & Avalanches & Rockfalls/debris flows & Earthquakes & Traffic & Work \\
\hline \multirow[t]{8}{*}{14} & True type & 5 & 76 & 7 & 0 & 0 \\
\hline & Identified type: & & & & & \\
\hline & Avalanches & 0 & 1 & 0 & 0 & 0 \\
\hline & Rockfalls/debris flows & 5 & 75 & 3 & 0 & 0 \\
\hline & Earthquakes & 0 & 0 & 4 & 0 & 0 \\
\hline & Traffic & 0 & 0 & 0 & 0 & 0 \\
\hline & Work & 0 & 0 & 0 & 0 & 0 \\
\hline & Correct detection ratio & $0 \%$ & $99 \%$ & $57 \%$ & - & - \\
\hline \multirow[t]{7}{*}{15} & True type & 93 & 51 & 7 & 123 & 6 \\
\hline & Identified type: & & & & & \\
\hline & Rockfalls/debris flows & 20 & 38 & 0 & 2 & 2 \\
\hline & Earthquakes & 0 & 0 & 3 & 0 & 0 \\
\hline & Traffic & 0 & 3 & 1 & 115 & 0 \\
\hline & Work & 0 & 2 & 0 & 1 & 3 \\
\hline & Correct detection ratio & $74 \%$ & $75 \%$ & $43 \%$ & $93 \%$ & $50 \%$ \\
\hline \multirow[t]{8}{*}{16} & True type & 21 & 58 & 7 & 0 & 21 \\
\hline & Identified type: & & & & & \\
\hline & Avalanches & 9 & 11 & 0 & 0 & 2 \\
\hline & Rockfalls/debris flows & 7 & 41 & 3 & 0 & 7 \\
\hline & Earthquakes & 0 & 0 & 4 & 0 & 0 \\
\hline & Traffic & 0 & 0 & 0 & 0 & 0 \\
\hline & Work & 5 & 6 & 0 & 0 & 12 \\
\hline & Correct detection ratio & $43 \%$ & $71 \%$ & $57 \%$ & - & $57 \%$ \\
\hline
\end{tabular}

\section{CONCLUSIONS AND SUMMARY}

An automatic detection and warning system for avalanches, rockfalls and debris flows has been presented for a hillside in the West Fjords. Recorded seismic signal is used to identify and quantify new events based on a nearestneighbour method, i.e. by comparing new events with old known events registered in a database. The system has been running since February 1996. The operation of the seismic measurement equipment has been stable and satisfactory, despite being operated in severe environmental conditions. A great deal of data has been obtained. Most of the data are from a concrete shed, but data have also been obtained from two other tracks where the sensors are located on rock outcrops close to the main paths. A website has been operational from 1997 but the detection process, database and presentation of detected events were upgraded and improved in 2004 and 2005. It takes $\sim 2$ min to update the watchman page in the wake of a recorded event. Initially alerts were sent by e-mail to key personnel, but with the improved system the alert is sent by SMS. There may be some delay in SMS alerts and it is therefore considered necessary to monitor the watchman page when there is an ongoing avalanche hazard.

The identification process is unsatisfactory using the present system. Too many events are incorrectly classified, i.e. real avalanches are classified as rockfalls/debris flows and vice versa. More confirmed events in the database should improve the reliability of the detection process. Ten parameters, each with a different purpose, are used to identify and quantify events. Parameters focusing on characteristic frequency are useful both to identify traffic and earthquakes. Parameters quantifying how impulsive an event is are useful to detect rockfalls. Parameters measuring energy are useful to size-classify events. Finally, it was necessary to introduce two parameters to identify unimportant (i.e. traffic-induced) signals. To improve the system it would be helpful to use online weather data (temperature and precipitation) from nearby weather stations, and use weather parameters in the classification process. The nearest-neighbour method for evaluating avalanche hazard is well known, but the way it is used here, by means of the above parameters to detect events, is new, to the authors' knowledge.

Traffic-induced events are only recorded in one of the paths, and fortunately the detection process is quite reliable in identifying these events. The detection of an earthquake is unreliable in all the paths. While it might be useful to combine signals from all the sensors to identify earthquakes more reliably, they are rare in the region and not of major concern. It should also be noted that local people are in most cases aware of what is happening on the Óshlí hillside when the system starts sending out an alert. The people know the weather situation and are therefore able to draw the right conclusions. Although the detection system could be improved, the warning system in its present stage of development provides useful and practical results for the watchmen. 
The sensitivity of the monitoring system seems to be satisfactory, i.e. it seems to be able to detect all events of concern. The most critical events that can be missed are small dry avalanches.

Although, the main aim of the system is to alert traffic on the road, the system also has some other benefits. The overall benefits can be summarized as follows.

Using information from the system it is possible to declare a preparedness phase or to close the road for safety reasons when avalanches start flowing or if the frequency of rockfalls or debris flows is above certain predefined criteria.

During a snowstorm, it helps crews decide when to start clearing snow in the wake of a storm.

It can be used as an indicator of avalanche threat for people and civil works at similar sites in the region, i.e. sites with a similar topography and weather conditions.

It can be used for avalanche, rockfall and debris flow research. With this system it is possible to time exactly when avalanches start flowing. By studying weather data and correlating this to the time of avalanche releases it may be easier to understand when and how an avalanche threat develops.

Finally, by installing a network of detection systems at new sites which are known to have different avalanche sensitivity with respect to weather conditions (direction of wind and precipitation), it is possible to obtain a network of indicators that can be used to declare an avalanche hazard or rockfall/debris-flow hazard at matching sites or nearest-neighbour sites. It should, however, be noted that for a newly instrumented site it takes time before reliable results can be obtained. The time depends on how frequent events are in the path under observation and how often it is possible to identify a recorded event by field inspection.

\section{REFERENCES}

Bessason, B., G.J. Baldvinsson and Ó. Thórarinsson. 1999. Skynjun og greining snjóflóða með bylgjumælingum. Reykjavík, University of Iceland, Engineering Research Institute. (Technical Report No. 99002.)

Bessason, B., G.J. Baldvinsson, Ó. Thórarinsson and G. Eiríksson. 2000. Detecting and analysis of avalanches using wave measurements. In Hjorth-Hansen, E., I. Holand, S. Løset and H. Norem, eds. Snow engineering: recent advances and developments. Rotterdam, Balkema, 33-40.

Biescas, B., F. Dufour, G. Furdada, G. Khazaradze and E. Suriñach. 2003. Frequency content evolution of snow avalanche seismic signals. Surv. Geophys., 24(5-6), 447-464.

Kishimura, K. and K. Izumi. 1997. Seismic signals induced by snow avalanche flow. Natur. Hazards, 15(1), 89-100.

Kristjánsson, O., F. Balvinsdóttir, G. Eiríksson and J. Helgason. 2002. Safety affairs on the Djúpivogur Road between Súđavík and Bolungarvík. Reykjavík Public Roads Administration. [In Icelandic.]

Lawrence, W. and T.R. Williams. 1976. Seismic signals associated with avalanches. J. Glaciol., 17(77), 521-526.

Leprettre, B.J.P., J.P. Navarre and A. Taillefer. 1996. First results of a pre-operational system for automatic detection and recognition of seismic signals associated with avalanches. J. Glaciol., 42(141), 352-363.

Marchi, L., M. Arattano and A.M. Deganutti. 2002. Ten years of debris-flow monitoring in the Moscardo Torrent (Italian Alps). Geomorphology, 46(1-2), 1-17.

Norwegian Public Roads Administration (NPRA). 1994. Snow engineering for roads: about snow avalanches and drifting snow. Oslo, Norwegian Public Roads Administration. (Håndbok 172.)

Suriñach, E., F. Sabot, G. Furdada and J.M. Vilaplana. 2000. Study of seismic signals of artificially released snow avalanches for monitoring purposes. Phys. Chem. Earth B, 25(9), 721-727.

Vanmarcke, E.H. and S.-S.P. Lai. 1980. Strong-motion duration and RMS amplitude of earthquake records. Bull. Seismol. Soc. Am., 70(4), 1293-1307. 